\title{
Finite element modelling of cable median barriers under vehicular impacts
}

\author{
J. Bi ${ }^{1}$, H. Fang ${ }^{1}$ \& D. C. Weggel ${ }^{2}$ \\ ${ }^{I}$ Department of Mechanical Engineering and Engineering Science, \\ The University of North Carolina at Charlotte, USA \\ ${ }^{2}$ Department of Civil and Environmental Engineering, \\ The University of North Carolina at Charlotte, USA
}

\begin{abstract}
Cable median barriers (CMBs) are safety devices installed on highway medians to prevent cross-median crashes. Although fatality rates decrease notably after installation of CMBs, a small percentage of vehicles are found to under-ride the CMBs and enter the opposing traffic lanes. Retrofitting the current CMBs could reduce the number of these events and further increase the reliability of these barrier systems. Owing to the high cost and restrictions of full-scale physical crash tests, detailed analysis and parametric studies of CMB designs have been recently oriented towards numerical modelling of vehicle-barrier impacts. In this study, a three-strand CMB system installed on a sloped median and impacted by a passenger vehicle is modelled and evaluated using the nonlinear finite element (FE) method. Detailed FE models of the CMB and the vehicle are presented. Various modelling issues involved in the nonlinear FE analysis, such as contact modelling and numerical instabilities, are discussed. Based on an analysis of vehicle-barrier interactions using FE simulations, a new CMB design is derived and its performance is compared to the current design.
\end{abstract}

Keywords: finite element modelling, cable median barrier, sloped median, roadside safety, cross-median collisions.

\section{Introduction}

Highway safety has been a public concern for decades. Over the years, researchers have developed several types of roadside safety devices including median barriers for preventing cross-median collisions. Depending on site 
conditions, rigid, semi-rigid and flexible barrier systems are considered and installed on U.S. highways; they must conform to guidelines provided by the American Association of State Highway and Transportation Officials (AASHTO [1-3]) and are obliged to satisfy the safety requirements specified by the NCHRP Report 350 (Ross et al. [4]).

As a flexible barrier system, cable median barriers (CMBs) are normally adopted for medians with a width of $7.3 \mathrm{~m}$, the minimum width to accommodate lateral cable deflections. Fatality rates decrease notably after installations of CMBs (Sposito and Johnston [5], McClanahan et al. [6], WSDOT [7], Ray et al. [8]), with an estimated reduction of 90 percent of the cross-median collisions. However, under certain site and impact conditions, a small percentage of the vehicles were found to under-ride CMBs and crash into vehicles in opposing traffic, causing fatal injury (Johnson et al. [9], MacDonald and Batiste [10]). These incidents require a more comprehensive evaluation of cable-vehicle interactions to increase the reliability of CMBs for small-vehicle impacts.

The design and evaluation of roadside safety devices were largely based on engineering experience and standardized physical tests (Bligh and Mak [11]). Given the high cost and restrictions of full-scale physical crash tests, attention was recently directed to numerical simulations of vehicle-barrier impacts that were made possible by the marked improvement in computer hardware and parallel computing (Ray [12], Ren and Vesenjak [13], Marzougui et al. [14], Marzougui and Opiela [15], Ulker and Rahman [16]).

In this paper, the performance of an in-service three-strand CMB under vehicular impacts is evaluated using numerical simulations. The nonlinear finite element (FE) models are created to simulate a small passenger vehicle impacting a CMB installed on a sloped median. Several modelling issues involved in the nonlinear FE analysis, such as contact modelling and numerical instabilities, are discussed. Based on an analysis of vehicle-barrier interactions using $\mathrm{FE}$ simulations, a new CMB design is derived and evaluated. The new design is shown to have better performance than the current design in preventing vehicles from under-riding the CMB.

\section{Problem description}

Vehicle under-riding was found to dominate reported cases of cross-median crashes involving $\mathrm{CMBs}$. In $\mathrm{CMB}$ under-riding, the cable heights in relation to the vehicle's bumper height are critical at the instant of impact. The interaction with cables affects the dynamic response of the vehicle after impact; this is the primary phenomenon studied in this paper. The North Carolina three-strand lowtension CMB is assessed in this study. The heights of the three cables - top, middle and bottom as shown in Fig. 1 - are defined as the vertical distance from the cable to the middle point of the post on the ground line.

The suspension of a vehicle is compressed as it crosses the bottom of the sloped median (see Fig. 2), resulting in a lowered bumper relative to the ground. Suspension compression is affected by the vehicle's speed and impact angle. To address the issue of vehicle under-riding, some of the cables in the current design 


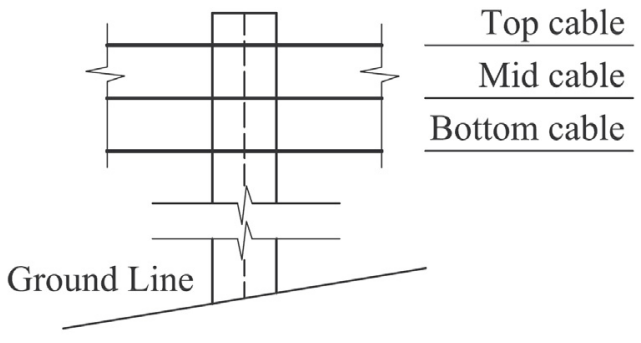

Figure 1: The three cables of a low-tension CMB.

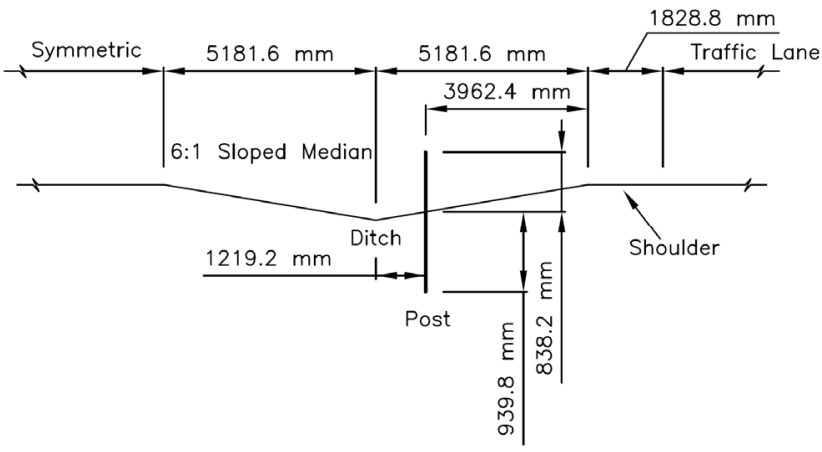

Figure 2: $\quad$ A North Carolina CMB installed on a 6:1 sloped median.

may need to be lowered to improve vehicle-cable interactions. Table 1 gives several design options that have different combinations of cable heights. The height of the top cable remains unchanged so that large vehicles can also be captured. For the bottom and middle cables, different height combinations are investigated to identify the design with better containment of small vehicles.

Table 1: $\quad$ CMB design options.

\begin{tabular}{cccc}
\hline \hline \multirow{2}{*}{ Design Option } & \multicolumn{3}{c}{ Cable Height (mm) } \\
\cline { 2 - 3 } & Bottom Cable & Middle Cable & Top Cable \\
\hline Current Design & 520.7 & 641.4 & \\
\hline Design 1 & 330.2 & 520.7 & \multirow{2}{*}{762.0} \\
\hline Design 2 & 355.6 & 558.8 & \\
\hline Design 3 & 381.0 & 520.7 & \\
\hline Design 4 & 381.0 & 571.5 & \\
\hline Design 5 & 431.8 & 596.9 & \\
\hline \hline
\end{tabular}

Table 2 provides the impact conditions of the FE simulations used for all design options. The $\mathrm{CMB}$ is located $1.22 \mathrm{~m}$ from the ditch centerline, and impacts from both front-side (the side without ditch) and back-side (the side with 
Table 2: $\quad$ Impact conditions for the FE simulations.

\begin{tabular}{cccccc}
\hline \hline Impact Side & Impact Angle & \multicolumn{4}{c}{ Impact Speed (km/hr) } \\
\cline { 1 - 4 } Front-side & $20^{\circ}, 30^{\circ}, 40^{\circ}$ & 88.5 & 104.6 & 112.7 & 120.7 \\
\cline { 1 - 4 } Back-side & & & & & \\
\hline \hline
\end{tabular}

ditch) are analyzed. For each side, a total of 12 conditions are simulated, three impact angles over four impact speeds.

The main focus of this study is to evaluate the vehicle's response after impacting the $\mathrm{CMB}$ to determine the best cable heights for a retrofit design. Vehicle responses are placed into one of four categories, as shown in Fig. 3, based on the effectiveness of the CMB in redirecting the vehicle. In Case A, the vehicle is redirected within the sloped median and its lateral velocity reaches zero. Cases B and C are similar to Case A, except that in Case B the vehicle is redirected on the shoulder and in Case $\mathrm{C}$ the vehicle is redirected in the opposing traffic lane. Case D refers to the scenario where the vehicle enters the opposing traffic lane and has a non-zero lateral velocity (i.e. the vehicle is not redirected). The $\mathrm{CMB}$ is considered effective for Cases $\mathrm{A}$ and $\mathrm{B}$ and to have failed for Cases $\mathrm{C}$ and $\mathrm{D}$.

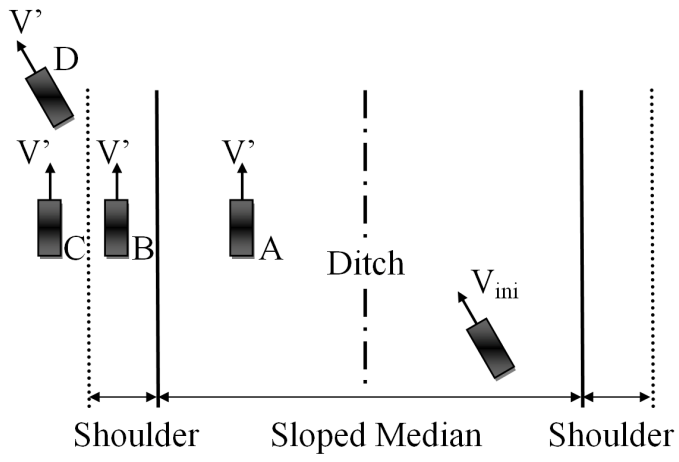

Figure 3: Vehicular responses after impact. A. redirection within sloped median; B. redirection on shoulder; C. redirection in opposing traffic lane; and D. penetration.

\section{Finite element modelling}

The FE models for the simulations in this paper include a vehicle, a CMB, and a sloped median. The CMB model was obtained from the National Crash Analysis Centre (NCAC) and modified according to NCDOT design specifications (NCDOT [17]). The vehicle model was also obtained from NCAC and modified to correct a number of modelling issues. These models were created for the nonlinear FE code, LS-DYNA (LSTC [18]), which is specifically formulated for dynamic transient analysis. In all simulations, the median slope was 6:1 
(horizontal:vertical) and the vehicle was assumed to be fully landed on the sloped median.

\subsection{Vehicle model}

The vehicle model contains a total of 336 parts, 283859 nodes and 270768 elements (2852 solids, 122 beams, 267786 shells and 8 other elements). 339 constitutive (material) models were used, including the piecewise linear plasticity model defined for most steel components, the elastic spring model for the shock absorber, the crushable foam model for the bumper, and the honeycomb model for the radiator core. Constraints within the vehicle are mostly modelled by rigid links and spot welds. Hourglass control was used on various components that could potentially experience large deformations.

Some shell elements were found to be disconnected and caused instabilities that terminated the simulations. Some shell elements were found to have small Jacobians (less than 0.6) and were unstable under large deformations. Constraints between tires and rims were missing and resulted in unrealistic tilting of the tires. All of these issues, along with a number of initial penetrations, were corrected to ensure simulation stability.

\subsection{CMB model}

A typical CMB section consists of cables, steel posts, hook-bolts, and reinforced concrete anchor blocks. The post and cable models are shown in Fig. 4. In the NCDOT design specifications (NCDOT [17]), a CMB section has approximately 120 -m of effective length (between the third posts from both ends). At a post spacing of $4.88 \mathrm{~m}, 28$ posts are required for each section.

The CMB model of this study was taken from a three-strand low-tension cable system used by WSDOT. The WSDOT model was validated with a fullscale crash test on a flat terrain; it was modified according to NCDOT design specifications (NCDOT [17]) and placed on a 6:1 sloped median in this study.

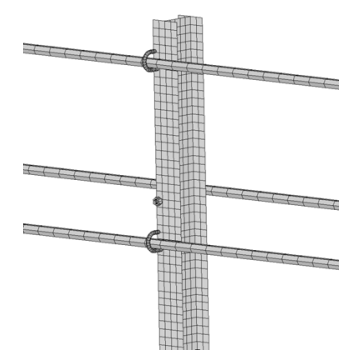

Figure 4: Modified post and cable model.

The modified CMB model includes a total of 555 parts, 148978 nodes and 143643 elements (580 solids, 13085 beams, 129880 shells and 98 other elements). The posts contain 91168 nodes and 87444 elements. The cables 
contain 48122 nodes and 46765 elements. The anchor blocks contain 9678 nodes and 9430 elements. The median contains 10 nodes and 4 elements. Eighteen material models were used including the piecewise linear plasticity, elastic, elastic spring, rigid, and null material models.

The cables were modelled with beam elements surrounded by six shells rigidly linked to both ends of each beam element. The six shell elements form a hexagonal cross-section that approximated the circular cross-sections of the cables. These shells were used only for contact purposes and were assigned with null materials so that they would not contribute to the mass or stiffness of the cables. The hook-bolts were modelled in the same way as the cables. However, the material properties of the beam elements of the hook-bolts were different from those in the cables. The compacted soil around the posts was modelled with solid elements in the original CMB model. Given the small deformations of the underground portion of the posts as observed in test simulations, the soil elements were removed and the posts were fixed below the ground surface; this approach also significantly reduced the computational cost.

The median (sloped region and both shoulders) was simply modelled using four shell elements. All degrees of freedom of all nodes were fixed to create rigid ground surfaces.

\subsection{Contact modelling}

Vehicle-cable interactions caused severe deformations and a large number of edge contacts that were difficult to handle in the FE simulations. Undetected contacts could cause unrealistic penetrations and result in numerical instabilities. The penalty method in LS-DYNA was used for contact force calculation in which the contact stiffness is determined by the material properties and size of the contacting surface. LS-DYNA supports several contact checking algorithms including nodes-to-surface, surface-to-surface and single-surface contacts. For nodes-to-surface contact, a slave and a master segment need to be defined. Each slave node is checked for penetration through the master segment. With detected penetrations, contact forces are calculated and applied to separate the two parts. For surface-to-surface contact, penetrations are checked both ways between the slave and master surfaces. For single-surface contact, only the slave segments are defined and penetration is checked within each and among all segments. Singlesurface contacts are commonly used in vehicle crash analysis due to the large number of potential contacts among components.

The simulations in this study involved contacts between cables and a large number of components of the vehicle that had complex geometries and could suffer large deformations. To handle this complicated situation, the automaticgeneral- interior contact algorithm in LS-DYNA was adopted to account for contacts, including both internal and external edges of shell elements.

The connections between the post flange and hook-bolts were originally modelled by a contact tie between the two. Since failure initiated from plastic yielding of either the hook-bolt or the post, the connection between them never failed during an impact. Therefore, these contact ties were replaced with rigidlink connections between hook-bolts and posts. Contacts between cables and 
posts were handled by the nodes-to-surface algorithm, which was also used for the contacts between the tires of the vehicle and the median surface.

\section{Simulation results and discussion}

The crash simulations were performed using LS-DYNA 971 running on eight nodes in parallel on a Linux cluster. The simulation results showed that the deformations of the vehicle during an impact were mostly located at the left frontal corner of the vehicle, including the bumper cover, fender, hood and several parts under the hood. Upon impacting the fender, the cables could fold the fender and engage with the internal parts. The cables could also slide up or slide down the vehicle without engagement, depending on the points of impact and the geometric features of the bumper, fender and hood. The simulation results confirmed the sensitivity of cable-vehicle engagement to impact location. It should be noted that some cables initially engaged with the vehicle for a short duration but eventually slid up or down the vehicle. In this case, these cables contributed to the retention of the vehicle but were less effective than those that engaged with the vehicle throughout the entire impact duration.

Figure 5 shows a typical scenario of cable engagements during impact. The top cable slides up the vehicle along the outer frame with no engagement. The middle cable deforms the fender inward and engages with parts in the engine compartment. The bottom cable engages with the bumper cover and the tire for a short duration and then slides under the vehicle. Since the kinetic energy of the impacting vehicle is generally absorbed by the deflections in cables and the resulting plastic deformations of hook-bolts and posts, more cable engagements would utilize more of the CMB's capacity to redirect the vehicle.

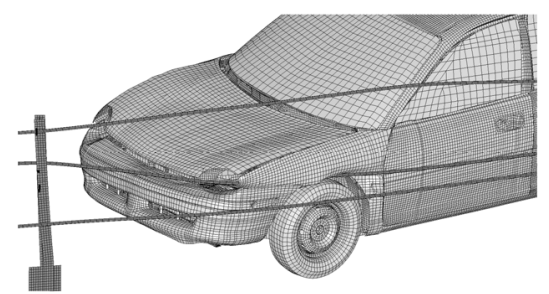

a.

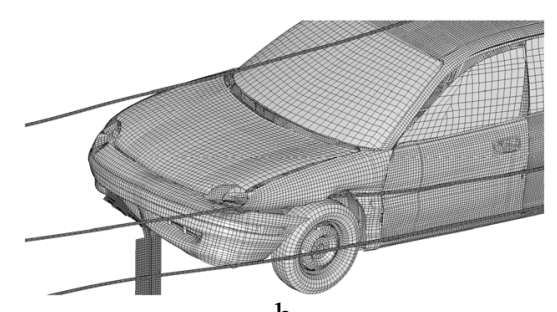

b.

Figure 5: Typical cable-vehicle engagement. a. $\mathrm{t}=0.15 \mathrm{sec}$; and $\mathrm{b}$. $\mathrm{t}=0.42 \mathrm{sec}$.

The current design and the five retrofit designs were run using the impact conditions given in Table 2. The current CMB design performed well in frontside impacts; the vehicle was redirected within the sloped median under all impact conditions. In the $20^{\circ}$ impacts, only the bottom cable engaged with the vehicle. In the $30^{\circ}$ and $40^{\circ}$ impacts, both the middle and bottom cables engaged with the vehicle providing more retention than that of the $20^{\circ}$ impacts. Figure 6 shows four snap shots of the front-side impact at $40^{\circ}$ and $120.7 \mathrm{~km} / \mathrm{hr}$. It can be seen that the front part of the vehicle (e.g., the hood and bumper cover) underwent severe deformations due to cable engagement. 
For back-side impacts, there was $2.44 \mathrm{~m}$ less median distance to redirect the vehicle. In all back-side impacts, only the bottom cable engaged with the vehicle due to the low vehicle profile from suspension compression. Consequently, the CMB failed to safely redirect the vehicle for $30^{\circ}$ and $40^{\circ}$ impacts. Moreover, yielding of the hook-bolts allows the cable to "unzip" from the post, further decreasing the stiffness of the system under these impact scenarios. Figure 7

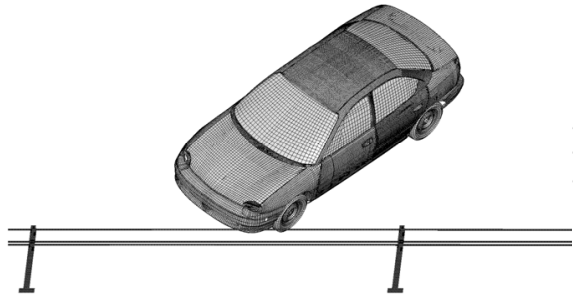

a.

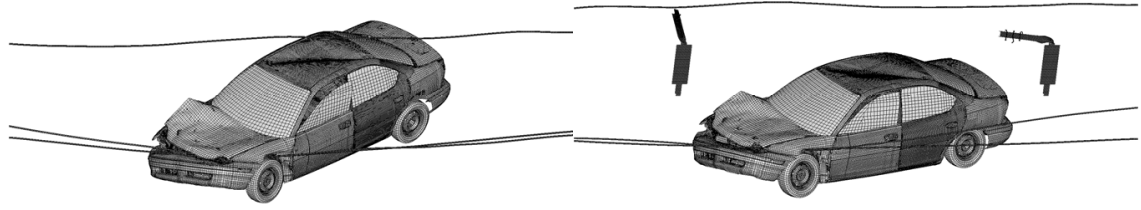

c.

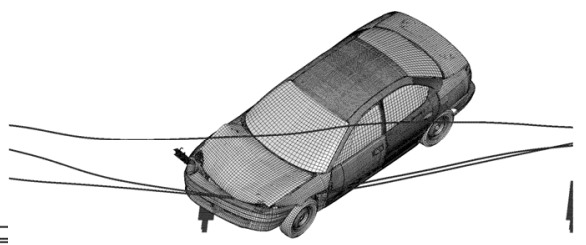

b.

d.

Figure 6: The current design under front-side impact at $40^{\circ}$ and $120.7 \mathrm{~km} / \mathrm{hr}$. a. $\mathrm{t}=0.00 \mathrm{sec} ; \mathrm{b} . \mathrm{t}=0.10 \mathrm{sec} ; \mathrm{c} . \mathrm{t}=0.20 \mathrm{sec}$; and $\mathrm{d}$. $\mathrm{t}=0.30 \mathrm{sec}$.

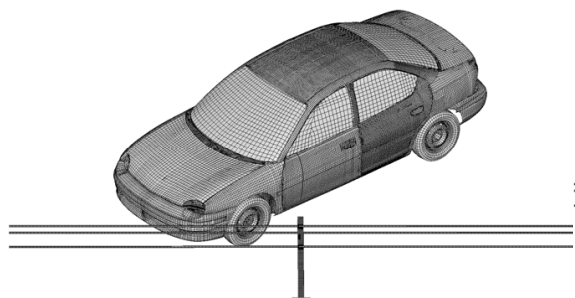

a.

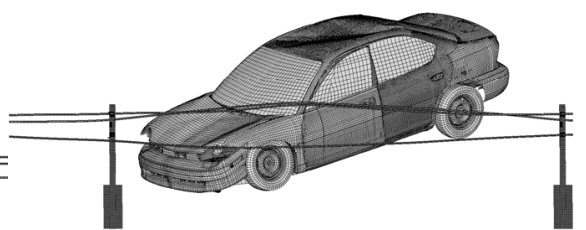

b.



c.

d.

Figure 7: The current design under back-side impact at $40^{\circ}$ and $120.7 \mathrm{~km} / \mathrm{hr}$. a. $\mathrm{t}=0.00 \mathrm{sec}$; b. $\mathrm{t}=0.10 \mathrm{sec} ; \mathrm{c} . \mathrm{t}=0.20 \mathrm{sec}$; and $\mathrm{d}$. $\mathrm{t}=0.30 \mathrm{sec}$. 
shows four snap shots of the back-side impact at $40^{\circ}$ and $120.7 \mathrm{~km} / \mathrm{hr}$. Severe deformations of the hood, fender, bumper cover, and the roof were observed. Based on the above analysis, a successful retrofit design should aim at increasing the system performance under back-side impacts, while maintaining good performance under front-side impacts.

Retrofit design 1 performed slightly better for back-side impacts. However, for front-side, $40^{\circ}$ impacts, the system became ineffective since the bottom cable did not engage with the vehicle. For the same reason, retrofit design 3 under $40^{\circ}$, front-side impacts performed worse than the current design. Since the bottom cable always slid under the vehicle in front-side impacts for retrofit designs 1 and 3, it was concluded that a cable height lower than $381 \mathrm{~mm}$ would be too low for effective engagement with the vehicle (for front-side impacts). It was further observed that the top cable (at $762 \mathrm{~mm}$ ) always slid over the vehicle, leaving only the middle cable to engage with the vehicle. However, as seen from simulation results of design 1, engagement with the middle cable alone was not sufficient to redirect the vehicle for $30^{\circ}$ and $40^{\circ}$ back-side impacts. Therefore, retrofit designs 1 through 4 were considered ineffective and thus abandoned. Despite this, simulation results confirmed the strong correlation between cable heights and vehicle-cable engagement.

An analysis of the simulation results showed that the cables were required to have a minimum height of $431.8 \mathrm{~mm}$ for front-side impacts. Cables lower than this height would be ineffective in engaging with small passenger vehicles. Cables at a height of $520.7 \mathrm{~mm}$ above grade were found to perform well for both front-side and backside impacts. Effective cable heights for backside impacts ranged from 431.8 to $571.5 \mathrm{~mm}$ for $20^{\circ}$ impacts, 355.6 to $520.7 \mathrm{~mm}$ for $30^{\circ}$ impacts, and 330.2 to $520.7 \mathrm{~mm}$ for $40^{\circ}$ impacts. Therefore, cable heights of 431.8 to $520.7 \mathrm{~mm}$ were considered the most effective for all the back-side impacts and were further investigated for the improved design in this study.

The cable-mounting options on the posts affect the resistance of the CMB. This is because more resistance can be provided by pushing the cable into the post and yielding it, than by just yielding a hook-bolt without yielding the post. It was therefore proposed in the improved design that the current cable installation sides be reversed (see Fig. 8). Once the bottom cable engaged with the vehicle impacting from the back-side, it would need to yield the post before being released and thus would provide more resistance to back-side impacts.

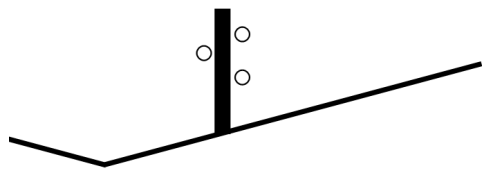

a.

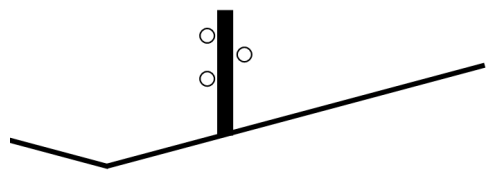

b.

Figure 8: Cable mounting options. a. current designs; and b. improved design. 
Based on the correlation of cable heights with cable-vehicle interactions, an improved design was suggested by mounting the three cables as shown in Fig. 8b at 431.8, 520.7, and $762.0 \mathrm{~mm}$ above grade. The simulation results of the improved design showed that the vehicle was successfully redirected for all back-side and front-side impacts. The redirection for back-side impacts was improved remarkably with full engagement of both the bottom and middle cables in all scenarios. Figure 9 shows a plan view of several snap shots of the simulation results for the current and improved designs under back-side impacts at $40^{\circ}$ and $120.7 \mathrm{~km} / \mathrm{hr}$. The current design showed no sign of redirection through $0.4 \mathrm{sec}$ after the impact; the vehicle's travel direction was nearly unchanged. In the improved design, the vehicle's travel direction changed significantly at $0.4 \mathrm{sec}$, and the vehicle was completely redirected by $0.6 \mathrm{sec}$.

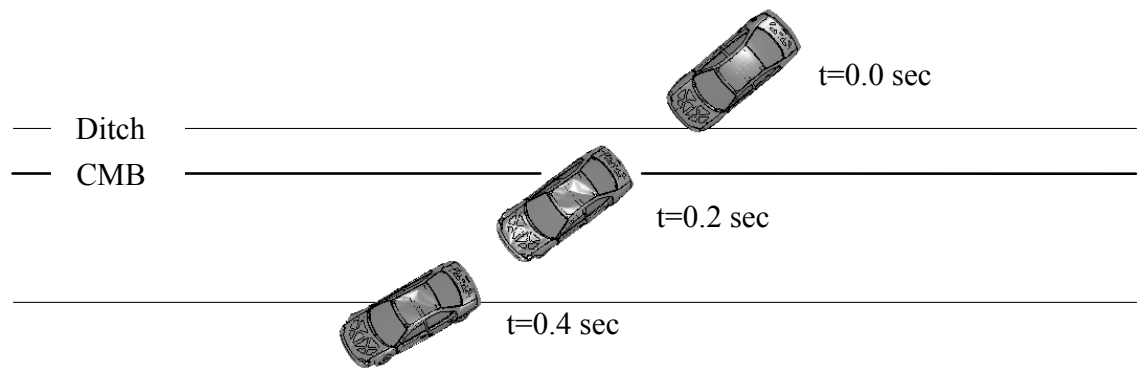

a.

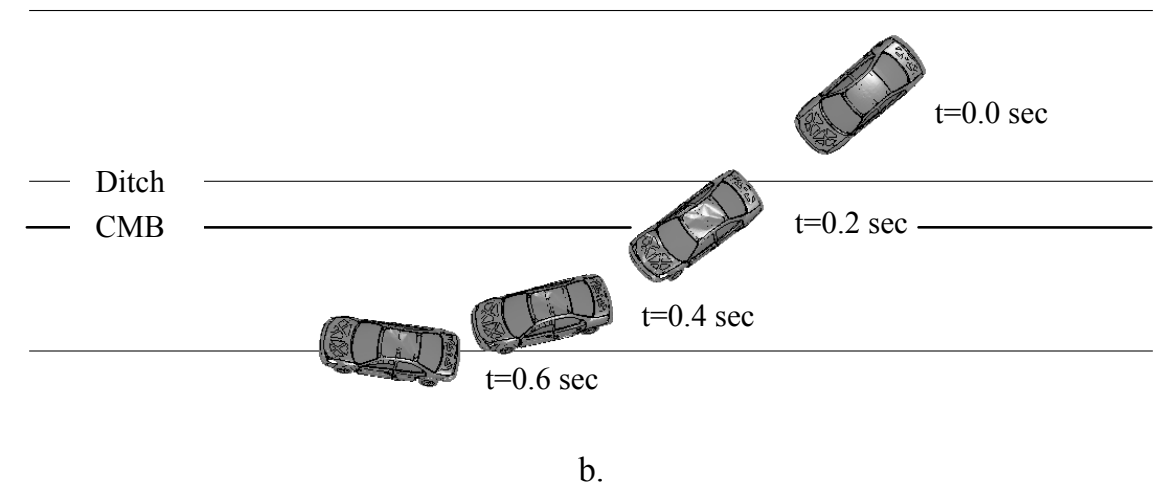

Figure 9: Vehicle redirection under back-side impacts at $40^{\circ}$ and 120.7 $\mathrm{km} / \mathrm{hr}$. a. current design; and b. improved design. 


\section{Concluding remarks}

In this paper finite element simulations were performed to evaluate the safety performance of a CMB installed on a 6:1 sloped median and impacted by a small passenger vehicle. The vehicle model was obtained from NCAC and was modified to accommodate sloped median crash simulations. The WSDOT CMB model was obtained and modified according to NCDOT design specifications (NCDOT [17]). Contact modelling, boundary conditions and numerical instabilities were discussed.

The in-service CMB design and five retrofit designs were evaluated over a range of impact conditions. Simulation results showed that cable heights were critical to cable-vehicle interactions. Engagement of more cables with the vehicle produces a higher effective resistance of the barrier and reduces CMB lateral deflections. It was shown that cables lower than $431.8 \mathrm{~mm}$ above grade are ineffective for front-side impacts. Cables 431.8 to $520.7 \mathrm{~mm}$ above grade are effective for back-side impacts; top cables $762.0 \mathrm{~mm}$ above grade always slide over the small-sized vehicle. Based on the analysis of cable heights, the improved design is proposed with bottom and middle cable heights at 431.8 and $520.7 \mathrm{~mm}$ above grade and the top cable height remains unchanged for the redirection of large-sized vehicles.

The cable mounting options on the posts also affect the resistance of the $\mathrm{CMB}$. This is because more resistance can be provided by pushing the cable into the post, and thus yielding the post, than just yielding a hook-bolt without yielding the post. The reversed cable mounting option was adopted in the improved design to maximize effective resistance of the CMB for back-side impacts. The improved design was proved capable of redirecting small vehicles under all the investigated impacting conditions.

\section{Acknowledgement}

This study was funded by the North Carolina Department of Transportation (NCDOT) under project No. 2008-10.

\section{References}

[1] AASHTO, 2002 Roadside Design Guide. American Association of State Highway and Transportation Officials, Washington, D.C., 2002

[2] AASHTO, Revised Chapter 6: Median Barriers, AASHTO Roadside Design Guide (Ballot Draft). American Association of State Highway and Transportation Officials, Washington, D.C., 2005

[3] AASHTO, Roadside Design Guide (3rd Edition) 2006, with Updated Chapter 6. American Association of State Highway and Transportation Officials, Washington, D.C., 2006

[4] Ross, H. E., Jr., Sicking, D. L., Zimmer, R. A., and Michie, J. D., Recommended Procedures for the Safety Performance Evaluation of 
Highway Features. Transportation Research Board, National Research Council, Washington D.C. (NCHRP Report 350), 1993

[5] Sposito, B., and Johnston, S., Three-Cable Median Barrier Final Report. Oregon Department of Transportation, Salem, 1998

[6] McClanahan, D., Albin, R. B., and Milton, J. C., Washington State Cable Median Barrier In-Service Study. 83rd Annual Meeting of the National Transportation Research Board, Washington D.C., 2004

[7] WSDOT, I-5 Marysville Cable Median Barrier. In: WSDOT Report, Washington State Department of Transportation, Olympia, WA, 2006

[8] Ray, M.H., Silvestri, C., Conron, C.E., and Mongiardini, M., Experience with Cable Median Barriers in the United States: Design Standards, Policies, and Performance. Journal of Transportation Engineering-ASCE, 135(10), 711-720, 2009

[9] Johnson, M., Zukowski, R., Andraschko, M., Austin, T., VerGowe, J., and Meyers, D., Collision Analysis and Reconstruction Report - Incident Report \# 2007-327-SE, 2007

[10] MacDonald, D. B., and Batiste, J. R., Cable Median Barrier - Reassessment and Recommendations. WSDOT Report, Washington State Department of Transportation, Olympia, WA, 2007

[11] Bligh, R. P., and Mak, K. K., Crashworthiness of Roadside Features across Vehicle Platforms. Transportation Research Record (1690), 68-77, 1999

[12] Ray, M. H., Use of Finite Element Analysis in Roadside Hardware Design. Transportation Research Board (453), 61-71, 1996

[13] Ren, Z., and Vesenjak, M., Computational and Experimental Crash Analysis of the Road Safety Barrier. Engineering Failure Analysis, 12(6), 963-973, 2005

[14] Marzougui, K., Mohan, P., Kan, C. D., and Opiela, K., Performance Evaluation of Low-Tension Three-Strand Cable Median Barriers. Transportation Research Record (2005), 34-44, 2007

[15] Marzougui, D., and Opiela, K., Evaluation of Rail Height Effects on the Safety Performance of W-Beam Barriers. In: 6th European LS-DYNA User's Conference, Gothenburg, Sweden, 2007

[16] Ulker, M. B. C., and Rahman, M. S., Traffic Barriers under Vehicular Impact: From Computer Simulation to Design Guidelines. Computer-Aided Civil and Infrastructure Engineering, 23(6), 465-480, 2008

[17] NCDOT, North Carolina Cable Guardrail Standard Drawings. http://tig.transportation.org/?siteid=57\&pageid=2041, 2006

[18] LSTC, LS-DYNA Keyword User's Manual. Livermore Software Technology Corporation, Livermore, CA, Version 970, 2003 